\title{
Salud Reproductiva e Interculturalidad
}

\author{
Reproductive Health and Interculturality
}

Adriana A. Feltri1, Jorge Arakaki2, Luis F. Justo3, Francisco Maglio ${ }^{4}$,

Florentino J. Pichún ${ }^{5}$, Martha I. Rosenberg6, Hugo Spinelli7,

Mario Testa ${ }^{8}$, Alicia M. Torres Secchi ${ }^{9}$, Roxana C. Ynoub ${ }^{10}$

${ }^{1}$ Médica generalista. Coordinadora de Epidemiología de la Zona Sanitaria II, provincia del Neuquén, Argentina. fliazapicofeltri@yahoo.com.ar

${ }^{2}$ Médico. Investigador y docente asociado en Gestión en Organizaciones de Salud. Universidad Nacional de Lanús, Argentina. arakaki_jorge@yahoo.com.ar

${ }^{3}$ Médico. Investigador y Profesor adjunto interino en la Cátedra de Bioética de la Universidad Nacional del Comahue, Argentina. ljusto@gmail.com

${ }^{4}$ Doctor en Medicina, Universidad de Bs. As. Académico de Número de la Academia Argentina de Ética en Medicina. Presidente de la Sociedad Argentina de Medicina Antropológica. adelaruibal@yahoo.com.ar

${ }^{5}$ Docente, miembro de la comunidad mapuche argentina.

pichunjorge@yahoo.com.ar

${ }^{6}$ Médica. Presidenta del Foro por los Derechos Reproductivos. Argentina. foroddrr@abaconet.com.ar

${ }^{7}$ Médico. Doctor en Salud Colectiva, Universidad de Campinas, Brasil. Director de la Maestría en Epidemiología, Gestión y Políticas de Salud de la Universidad Nacional de Lanús, Argentina.

hugospinelli@ciudad.com.ar

${ }^{8}$ Doctor Honoris Causa, Universidad Federal de Bahía, Brasil. Profesor titular de la Maestría de Epidemiología, Gestión y Políticas de Salud de la Universidad Nacional de Lanús. Argentina. mtesta@mail.retina.ar

9 Licenciada en Psicología, Especialista en Planificación y Administración Sanitaria. Gerente de Atención a las Personas. Hospital "Dr. Ramón Carrillo". Iruya, Salta, Argentina. aliciatorres_t@hotmail.com

10 Doctora en Psicología. UBA. Profesora Titular Regular de Introducción a la Investigación

Psicológica. Universidad Nacional de Mar del Plata, Argentina. rynoub@fibertel.com.ar
RESUMEN Este artículo de opinión ha sido realizado por varios autores en base a un texto que relata el conflicto suscitado entre la comunidad mapuche y una médica del sistema de salud de la provincia del Neuquén, al incorporarse a las mujeres de la comunidad al programa de salud sexual y reproductiva.

Los participantes expresan sus opiniones en dos rondas: en la primera se refieren específicamente al texto y en la segunda comentan las exposiciones de la primera.

Entre los tópicos analizados con mayor profundidad se destacan los vinculados con la normatividad en las intervenciones de los sistemas de salud y con las relaciones de poder que se producen entre ambos géneros y entre las diferentes culturas.

PALABRAS CLAVE Género y Salud; Cultura; Planificación Sanitaria; Etnia y Salud; Salud Sexual y Reproductiva.

ABSTRACT This opinion piece by several authors is based on a text that describes the conflict between the Mapuche community and a physician from the health-care system of the province of Neuquén when the Mapuche women entered the sexual and reproductive health program.

Opinions are expressed in two different ways: first, with specific reference to the text and then, as a subjective elaboration.

Among the issues analyzed in more depth are the regulations governing health-care system interventions and the power relations between genders and among different cultures.

KEY WORDS Gender and Health; Culture; Sanitary Planning; Ethnic Group and Health; Sexual and Reproductive Health. 


\section{INTRODUCCIÓN}

Es probable que muchos trabajadores de la salud se vean reflejados en el relato de la Dra. Feltri, y que en su propia experiencia se hayan encontrado también con que el conocimiento y la capacitación acumulados en las distintas carreras o en los cursos de postgrado no aseguran la comprensión del semejante, y que la planificación no garantiza ni la pertinencia ni la viabilidad de las acciones. El desconcierto suscitado por las actitudes de alejamiento o indiferencia por parte de las comunidades, supuestas beneficiarias, puede alimentar el escepticismo y llevar a la inacción y la inercia o, por el contrario, puede inducir al esfuerzo del análisis y la reflexión. En esta postura enmarcamos la propuesta de este artículo.

Las acciones sanitarias, las intervenciones médicas especialmente, no son neutras. En ellas se producen y reproducen relaciones y enfrentamientos de poder, políticos, económicos, de saberes, de culturas, en la extensa variedad que la sociedad genera. En el relato, estas relaciones reflejan la asimetría claramente; por un lado, los representantes formales e institucionalizados de la cultura dominante y por el otro, las personas que se acercan buscando alivio para sus dolencias. Las tensiones que se producen en estas situaciones pueden quedar encubiertas bajo los pliegues de la timidez, la cortesía y la tolerancia, hasta que el choque con reglas y valores fundamentales descubre, inevitablemente, las contradicciones ocultas.

$\mathrm{Ni}$ las buenas intenciones, ni la calidad de la atención brindada legitiman las acciones que ejerce el Estado a través de sus sistemas de salud, si no se comparten con las comunidades los significados culturales y el sentido de las acciones en cada contexto.

La doctora Feltri define al sistema sanitario de la provincia como un modelo de planificación normativa, denominación que produce cierta remembranza de tiempo superado. Sin embargo, no debería sonar extraña a nuestros oídos, ya que, disimulada bajo otras denominaciones, en muchos lugares y servicios de nuestro país, la normatividad continúa siendo la regla y no la excepción, lo cual no es extraño, ya que la lógica que sustenta lo normativo permanece vigente en el medio.
El objetivo de este artículo es abrir un espacio de opinión y participación para la conceptualización de los temas de la cotidianidad que permiten, o más exactamente exigen, ser abordados desde diferentes perspectivas. No hay la pretensión de agotar los temas ni de concluirlos. Este objetivo, que anima también a la sección, se inscribe en los lineamientos generales de la revista.

\section{METODOLOGÍA}

Este artículo está dividido en tres partes: relato, primera ronda de opinión y segunda ronda de opinión.

El relato narra una experiencia vivida con intensidad por la autora, por la variedad temática que reúne y porque las preocupaciones y reflexiones que despierta están totalmente vigentes.

Las opiniones corresponden a varios autores invitados en forma directa por los editores (a), en virtud de su experiencia en temas relacionados con el texto: Salud Reproductiva, Género, Planificación, Psicología, Cultura, Ética y Salud. Estos participantes emitieron sus opiniones por escrito, en dos rondas. La primera estuvo referida directamente al texto, sin preguntas orientadoras ni consignas para su desarrollo. Estas exposiciones fueron circuladas entre todos quienes, en base a ellas, realizaron su segunda intervención.

El orden de las participaciones en el artículo intenta dar cierta continuidad argumental apuntando a una lectura más fluida.

\section{RELATO: MALLÍN (b) \\ POR ADRIANA A. FELTRI}

Completé mi formación médica en la residencia de un hospital de complejidad VI de la provincia de Buenos Aires, con el objetivo puesto en trabajar en el Sistema de Salud neuquino.

Allá por 1991, logré ingresar en él y comencé mis tareas en Neuquén como médica general, en un hospital de nivel III del interior, en la zona sanitaria ubicada en el centro de la provincia, a unos 30 kilómetros del Hospital Zonal de referencia. 
El hospital se encontraba frente a la plaza principal de un pueblo pequeño con cerca de 1.500 habitantes en su casco urbano, a cargo de una inmensa área rural con parajes más o menos alejados, con heterogénea distribución demográfica y variada composición étnica, con algunas comunidades de "huincas" (léase gente como uno, descendientes de extranjeros de muy diversos orígenes), y otras de descendientes de pueblos originarios de la región (para ser honesta, en 1991 hubiese escrito reserva aborigen, lo cual daría tela para mi propia autocrítica, que no sé si viene al caso hacerla en este momento).

Mi paso por la residencia me había inclinado a una normatización de todos los eventos y/o acontecimientos que pudieran presentarse. Normas que, tal como se dice en la Maestría (c), "simplifican los problemas" y "tranquilizan al colega".

La provincia desarrolló un sistema de salud basado en un modelo de planificación normativa (aclaro que sin haberle puesto esta denominación, en ese entonces constituía mi gran motivación: "un sistema organizado con normas claras a cumplir"). Normas que, no quepa ninguna duda, estaba dispuesta a respetar a rajatabla (como diría mi abuelita).

Una de las normativas vigentes en aquel momento, y aún hasta la fecha, es la entrega gratuita de anticonceptivos a todas las mujeres que pisen suelo neuquino y que los requieran (a esto lo llamamos ahora "salud sexual y reproductiva", antes era "planificación familiar"). Yo pensaba, y sigo pensando, que cualquiera sea el título impreso, sigue siendo planificación normativa y sistemática por parte del poder.

Mi relato, entonces, está ambientado en uno de los parajes del área rural que periódicamente visitábamos. Su población estaba esparcida en una zona al noroeste del hospital, a unos 120 kilómetros, distancia que había que recorrer por caminos vecinales de muy difícil acceso.

Los pobladores integran una de las muchas comunidades mapuches aún establecidas sobre el Neuquén. Su cacique era, en ese momento, el hijo mayor de una de las familias más "numerosas" del lugar.

Me posicioné con esmero ante este tema de planificar las familias, y aprovechando las visitas médicas que nos acercaban al lugar, promocionaba las bondades de los métodos.
Es importante aclarar que en los encuentros que se realizaban en la escuela albergue del lugar participábamos, por un lado, el equipo de salud integrado por el chofer, un agente sanitario, el odontólogo y el médico general. Por otro lado, el de educación, formado por la maestra y el portero del establecimiento, y por parte de la Comunidad se acercaban las mujeres y sus niños, en su mayoría pequeños, y las ancianas en busca de tratamiento, para sus males crónicos y para sus familiares.

La promoción por mí realizada comenzó a dar sus frutos. A los pocos meses, las "mujeres" ya estaban incluidas en el plan. Como es de suponer, nos empeñábamos más con aquellas cuyas familias eran más numerosas, que eran, para dar un ejemplo, la del portero de la escuela y la del cacique de la comunidad, cosa que no había tomado en cuenta en aquel momento.

Tiempo después, al llegar al paraje en una de las visitas periódicas, me encontré con que la maestra me solicitaba que me hiciera presente en la Dirección, pues habían concurrido los "hombres" de la comunidad para hablar conmigo.

Confieso que tragué saliva con mucha dificultad y hubiese deseado estar a miles de kilómetros de distancia del lugar; no obstante, asumí mi posición como "doctora" del sistema y encaré la situación.

El encuentro fue molesto para ambas partes, pero podía percibirse que "los hombres" tenían muy claro para qué estaban en ese incómodo lugar, cosa que no ocurría conmigo.

Quien conoce al pueblo mapuche (yo iniciaba mis escasos conocimientos en aquellos tiempos) sabe que son "gente de pocas palabras", pero puedo asegurar que estas, aunque pocas, fueron muy precisas, y si bien pueden no ser textuales, ya que no fueron escritas por mí en aquel momento, el sentido de las expresiones me quedaron bien grabadas: "Doctora, necesitamos que nos explique por qué nuestras mujeres no se enferman desde que usted está viniendo a verlas" (enfermar debe leerse como quedar embarazada, al igual que aliviar se refiere a parir).

El que hablaba era el portero de la escuela, quien me recibía en todas las visitas, sistemáticamente, con mate y tortas fritas, y era padre, en aquel entonces, de once hijos. Su mujer estaba en mi lista de "procreación responsable". 
Es necesario agregar, también, que en la reunión, entre los ocho hombres, no estaba presente el cacique (luego aprendí que por más médica que fuera, yo era una mujer, y él no me dirigiría la palabra), su prole era también de once hijos, aunque aventajaba al portero por varios varones, evento valioso si los hay en esta historia, y cuya esposa también me visitaba mensualmente.

Volviendo a la pregunta que me formularan, intenté explicar que yo no había forzado a nadie, que las mujeres habían "participado" en la elección del método, que yo sólo entregaba anticonceptivos a quienes lo solicitaban. Que era para que no siguieran naciendo tantos niños, los cuales (según mis valores), no iban a tener "todas las posibilidades" de alimento y educación necesarias, etc., etc., etc. tras lo cual me contestaron: "usted, doctora, debió consultarnos sobre el tema, pues usted no comprende el valor que representan los hijos para nosotros" y concluyeron: "doctora, esto se terminó aquí".

Regresé al hospital y llamé a reunión al "consejo asesor", en aquel momento mis dos compañeros médicos generales, una mujer y un varón, a quienes relaté el episodio. Lamiendo la herida inferida a nuestro orgullo profesional, lejos de replantearnos a fondo nuestra actitud, pero comprendiendo que la norma iba más allá de los límites tolerables por esta comunidad, decidimos realizar una reunión con "las mujeres" del Mallín, reproduciendo ante ellas la reunión que yo había mantenido en la escuela. Escucharon en silencio, y no se expresaron con palabras, pero no solicitaron más métodos anticonceptivos.

El portero va por 14 hijos. El cacique sigue ostentando su cargo, gracias al voto de los hombres de su familia.

Nosotros no avanzamos en el análisis, lo cual expresa nuestra coherente actitud frente al poder, en este caso al instituido en esa comunidad.

\section{PRIMERA RONDA DE OPINIONES}

FLORENTINO J. PICHÚN: Leí el trabajo de Adriana y entiendo su preocupación, sobre todo si nos ubicamos en la década del '90 que, aunque no sea mucho tiempo hasta hoy, la cosmovisión del poblador rural fiscalero y de los mapuches ha cambiado, debido a la comunicación establecida con la cultura occidental, las comunicaciones vía tecnológica, radio, televisión, etc., como también visitas sanitarias a los parajes rurales de la provincia, etc.

Volviendo al tema que nos ocupa, seguramente en ese momento el choque cultural tuvo un impacto fuerte porque este tema de la planificación familiar contradice la naturaleza de la cultura mapuche. La procreación es una manera natural de trascendencia y supervivencia étnica, en especial los hijos varones, además de ser un bien en sí mismo que conforma el capital social de sus comunidades.

Con relación a quién toma la decisión, siempre va a ser el varón de mayor edad, de mayor sabiduría de la familia: es una tradición mapuche y en ningún caso participa la mujer o los hijos chicos, porque esas son cosas de grande.

En cuanto a considerar un embarazo como enfermedad, es porque durante la gestación la mujer está imposibilitada para realizar algunas tareas cotidianas, a las que volverá nuevamente después de parir, mejorarse.

Acerca de la planificación indicativa o normativa, personalmente no la comparto en ningún caso, menos aún en estos casos de diversidad cultural y étnica donde el criterio de otredad debería ser el primero en considerarse. Aquí es aconsejable planificar participativamente teniendo en cuenta la diversidad étnica-cultural con un grado de flexibilidad y evaluación permanente que permita un trabajo sanitario considerando el aspecto cultural del hombre mapuche.

FRANCISCO MAGLIO: Ante todo quiero señalar que es un texto sincero $y$, por lo tanto, valiente; y aclarar que el término "huinca" en mapuche significa: "extranjero ladrón".

Estoy de acuerdo en que las "normas simplifican los problemas y tranquilizan al colega", sobre todo cuando dichas normas se establecen desde un sanitarismo pedagógico-disciplinar, y en consecuencia intervencionista en otras culturas desde una posición socio-centrista, con objetivos de control social y normatividad desde el poder de un modelo médico hegemónico.

En mi opinión, por supuesto opinable, valga la redundancia, cuando se quiere desarrollar 
un programa de salud en una comunidad culturalmente distinta a la nuestra, el primer paso es justamente una investigación antropológica sobre cuáles son los determinantes socio-culturales del proceso salud-enfermedad-atención en esa comunidad.

En consecuencia, tendría que haberse estudiado previamente cuál es el sentido cultural de la multiparidad en esa comunidad.

Desde nuestro sociocentrismo asociamos frecuente y equivocadamente la multiparidad como sinónimo de ignorancia y causa del subdesarrollo, cuando en realidad es al revés: no es la causa sino el producto del mismo, ya que es una estrategia de supervivencia. En situaciones de extrema pobreza, un chico produce más de lo que consume.

Por otra parte, como surge del texto que nos ocupa, la multiparidad en esa comunidad es una estrategia cultural de defensa y subsistencia frente al avasallamiento del "huinca", que no solamente los limita a una "reserva" en términos de territorio, sino también en la limitación de un desarrollo demográfico.

Vale decir que, en este caso, la multiparidad tiene un valor simbólico de "reserva" cultural y antropológica.

Ahora bien, como dice Eduardo Menéndez en "Medicina y cultura" (1), los estudios antropológicos no deben quedarse solamente en la "belleza de lo simbólico" sino que deben avanzar en las posibles causas de morbimortalidad de lo simbólico.

Por lo cual, se tendría que haber estudiado previamente la morbimortalidad materno-infantil ligada a la multiparidad, y en caso de encontrarse esto, informarlo a la comunidad, especialmente en este caso, en primer lugar a los hombres por ser (aunque no guste desde una mirada femenina) los "interlocutores" válidos ante las mujeres.

Una aclaración final: en lengua mapuche embarazarse es ir a ser "ñuque" (madre). Cuando dicen embarazada como "enferma", no lo hacen desde su cultura sino desde la nuestra, que a las embarazadas las llamamos "pacientes" (enfermas).

ROXANA YNOUB (d): “QQué es y qué debe ser?" En torno a estas dos cuestiones se organiza toda la acción médica, o, para ser más amplios, toda acción regulativa. La determinación (intelectiva/valorativa) de un estado de situación (“¿qué es?") se realiza sobre la base de un horizonte de deseabilidad ("¿qué debe ser?").

A los efectos de examinar estos postulados, llevémoslos al terreno específico al que nos convoca la Dra. Feltri: ¿en qué situación se encuentran la salud reproductiva de la comunidad Mallín? Y consecuentemente con ello, ¿qué es deseable cambiar de ella y qué no?

Para responder a esta cuestión, es necesario averiguar desde dónde se interroga: ¿desde la propia comunidad (a través de sus representantes y portavoces), desde el Estado (a través, entre otros, de su sistema de salud); desde el mercado (a través de sus múltiples protagonistas locales)?

Cada uno de estos sujetos (la comunidad, el estado, el mercado) tiene posiblemente percepciones distintas acerca de cuáles son los problemas y necesidades de la comunidad, acerca de cuáles son las estrategias para resolverlos, acerca de qué es lo deseable para la "salud de la comunidad en general, y de su salud reproductiva en particular".

Desde los albores de la modernidad, y en el marco de una concepción fuertemente funcional a los intereses del mercado naciente, se concibió como un valor jurídico supremo la "libre individualidad", según la cual los intereses y derechos del individuo constituyen el bien supremo a proteger (e). De acuerdo con ello, se trata de estimar lo deseable para el individuo -definido éste abstractamente, es decir, con independencia de sus contextos y situaciones específicas- y consecuentemente fijar acciones tendientes a consumar esa transformación buscada.

En el caso particular de los derechos vinculados a la potestad para planificar y decidir sobre el número de hijos, la legislación fue variando en torno a la cuestión de la titularidad de esos derechos: en los años sesenta se reconocía a la familia, luego en los setenta y ochenta ya se había convertido en la pareja, y la tendencia actual apunta a proponer a la mujer como titular directa y primera (3)

Desde la perspectiva de la larga lucha por los reconocimientos a los derechos de las mujeres, esta tendencia habría que valorarla como positiva. Sin embargo, si se piensa en "la" mujer, con independencia de los contextos en 
que ella vive y se realiza, el derecho en sí mismo terminará por no impactar en las condiciones de vida reales de las mujeres a las que busca proteger.

La libre "individualidad" que la modernidad erigió en valor supremo, y que el sentido común (burgués) traduce como "elegir y actuar conforme a los propios fines" oblitera un hecho decisivo. El individuo no constituye nunca una unidad homogénea y clausurada al interior de sí. Por el contrario, es siempre parte de un contexto mayor, y contexto de una pluralidad de partes. La constitución de la subjetividad humana resulta de la inscripción en variados contextos socialmente instituidos (entendiendo por ellos contextos tan variados como los vínculos de parentesco, la familia, la comunidad, el estado, el mercado, por citar los estratos más relevantes). Esas experiencias de "inscripción subjetiva" forjan la conformación misma de la identidad humana. Los sujetos se determinan y se realizan según se determinen y se realicen dichos contextos; y concomitantemente, dichos contextos se realizan en tanto se realizan sus partes constitutivas. En lenguaje más Ilano eso implica, por ejemplo, que una comunidad no puede realizarse sino a condición de que se realicen sus miembros y sus familias, $y$ viceversa: en tanto estos se realizan, realizan a la comunidad de la que participan.

Esta dialéctica abre una dramática tan difícil como esperanzadora: difícil porque en toda realización del todo hay algún sacrificio de la parte (todo miembro familiar conoce, por experiencia, que para que la familia se realice está obligado a ciertas renuncias, a cierta entrega de su parte). Esperanzadora porque el todo debe servir y potenciar a la parte de la que se nutre (la familia, a su turno, consagra y confiere al miembro familiar una identidad, una función, una pertenencia vital y cultural).

Conforme a esta concepción, lo patológico quedaría definido por un vasallaje del todo sobre la parte o de la parte sobre el todo: cualquier acción arbitraria, violenta, etc. de una parte sobre otra lesiona ipso facto no sólo a la parte sino al todo mismo. De igual modo, el todo puede impedir, negar la realización de la parte (la familia sacrificar a sus miembros; el estado a sus comunidades, etc.).

De acuerdo con ello -y para ir directamente al tema que nos ocupa- la "elección" sobre el número de hijos, la maternidad, etc. no es un asunto domiciliado en una suerte de individualidad que se determina per se, en este caso en las mujeres de la comunidad.

Qué es y qué deja de ser la maternidad, la fecundidad, (es decir cuáles son los valores y los desvalores asociados a ella) está determinado por múltiples contextos en que las mujeres y sus familias se inscriben (vale aclarar que esto no le ocurre sólo a las mujeres de los pueblos originarios, sino a cualquier mujer de cualquier posición social en cualquier parte del planeta).

En este caso particular interesa muy especialmente recordar, que se trata de mujeres pertenecientes a una comunidad diezmada colonialmente. Una alta tasa de fecundidad podría constituirse en un bastión relevante en el marco de su resistencia anticolonialista. Cualquier "elección" posible y en todo caso "libre" sobre el número de hijos que estas mujeres desearían tener, las convoca desde los múltiples planos en que ellas se realizan: desde sus cuerpos; desde su pertenencia y linaje familiar, desde su función y compromiso político e incluso desde la compleja y desventajosa participación en el mercado capitalista (que de manera más o menos directa penetra aún en las comunidades más aisladas).

La acción en salud puede plantearse entonces desde dos perspectivas distintas, cada una de las cuales se corresponde con distintos tipos de políticas (o de Estado): una perspectiva basada en una concepción unilateral de planificación, conforme a la cual la gestión y la planificación queda del lado de los efectores (es decir, del propio Estado); otra, basada en la incorporación de la propia comunidad (o más ampliamente de los destinatarios de las políticas) como parte estratégica en la planificación y gestión de la atención en salud.

La primera opción implica cierto avasallamiento del "todo sobre la parte". Podría ser el caso, por ejemplo, que una política estimada como saludable desde la perspectiva del Estado no resulte saludable para la comunidad que la recibe -en esta ocasión, podría ser que la política de salud, destinada a las mujeres de la comunidad, atente contra la salud misma de toda la comunidad- en tanto beneficia, por ejemplo, a terratenientes que aspiran a resolver de la manera más económica -política y socialmente 
hablando- la invasión a las tierras de los pueblos originarios (haciendo que nazcan pocos y dejando en manos de la "pobreza" la muerte del resto).

La segunda opción, en cambio, implica incorporar protagónicamente a los destinatarios de las políticas.

La aplicación de esta opción, en el contexto de la experiencia que relata la Dra. Feltri, hubiese significado no sólo convocar a las mujeres para que "libremente decidan", sino hacer partícipe a toda la comunidad para que, a la luz del examen de su historia, de su situación político y social y de sus propias contradicciones internas, resuelvan y asuman las estrategias más deseables para definir su salud sexual y reproductiva.

No hay que olvidar que la comunidad constituye también una totalidad conformada por partes, que ostenta distintos niveles de determinación y, por lo tanto, distinto tipo de contradicciones entre ellos (en las que se incluyen seguramente cuestiones de roles y estatus vinculados al género). Los procesos de salud/enfermedad resultan seguramente del interjuego de estas relaciones al interior de la comunidad, conjuntamente con las que remiten al exterior de ella (entre las que se incluye el sistema de salud de la provincia, los vínculos que se han ido estableciendo con los efectores locales, las luchas de resistencias anticolonialistas, etc.).

Conforme a este segundo tipo de políticas, no se trata de actuar sobre poblaciones o individuos, sino también y especialmente sobre procesos representacionales que tengan en cuenta los contextos histórico-formativos, no sólo de las realidades en las que se va a trabajar, sino también de los propios agentes de salud.

Llevar adelante políticas de este tipo, exige en primer lugar que la formación profesional de los trabajadores de la salud no esté limitada a la administración de tareas prefijadas de manera universal, rígidas y centralizadas. Se requiere en cambio:

“...un 'agente autónomo' que dispone de habilidades y conocimientos aptos para descubrir, idear o crear la tarea que se deberá cumplir en un objeto/sujeto que no admite pasivamente cualquier propuesta, sino sólo aquellas que comienzan por reconocer su dignidad o agentividad subjetiva. Es decir, que comienza por admitir que el mundo de la población destinataria no es el mundo definido por los organismos estatales, sino el mundo creado por sus propias representaciones $u$ operaciones cognoscitivas instituyentes como 'estas familias' y 'estas comunidades particulares', con sus propias narrativas" (4).

Entiendo que en esa dirección se inscribe la mirada autocrítica, reflexiva y con vocación transformadora que nos transmite la Dra. Feltri.

LUIS JUSTO: El plan de salud neuquino puede ser considerado para su tiempo como un plan de avanzada, término que reconoce dos acepciones posibles según la Real Academia. La primera de ellas se refiere a una "partida de soldados destacada en el cuerpo principal, para observar de cerca al enemigo"; y la segunda, más común, a "lo que se adelanta, anticipa, o aparece en primer término" y "se distingue por su audacia o novedad". Y de ambas formas puede ser visto el sistema de salud en la provincia de Neuquén. En efecto, si bien este sistema fue y es considerado en los medios vinculados a la salud como uno de los primeros programas articulados de atención primaria de la salud (junto al de Jujuy), puede considerárselo también como una propuesta biopolítica, destinada a controlar exitosamente a los cuerpos de la geografía provincial, colaborando con un disciplinamiento aún presente en las prácticas políticas provinciales. Un rasgo de adecuación a tal finalidad puede hallarse en la presencia de los agentes sanitarios, a mitad de camino entre su pertenencia a la comunidad y sus creencias, y la "ciencia" representada por el Plan de Salud, cuyas normas debían ser implementadas sin excepciones, a riesgo de recibir evaluaciones críticas del sistema. Un minucioso protocolo de registro de las viviendas de los pobladores y sus hábitos corrobora la vigilancia "panóptica". Los desvíos son sancionados y las conductas prescriptas son implementadas a veces coactivamente. El parto debe ser institucional, y las tasas de morbilidad materna y neonatal deben bajar. Son imperativos ilustrados puestos en práctica desde una mirada colonial, sobre los cuerpos de otros excluidos de la toma de decisiones al respecto, cuya alteridad no se reconoce o no se toma en cuenta. 
La narración de Adriana Feltri describe con precisión una situación de normatividad en el contexto de un conflicto intercultural no planteado, de violencia epistémica hacia el otro. Dice Castro Gómez (5):

"De lo que se trataba era de ligar a todos los ciudadanos al proceso de producción mediante el sometimiento de su tiempo y de su cuerpo a una serie de normas que venían definidas y legitimadas por el conocimiento. Las ciencias sociales enseñan cuáles son las 'leyes' que gobiernan la economía, la sociedad, la política y la historia. EI Estado, por su parte, define sus políticas gubernamentales a partir de esta normatividad científicamente legitimada".

Esto presupone una "invención del otro", que a menudo implica su invisibilización, fenómeno existente en el sistema de salud neuquino hasta la actualidad. No existen programas destinados al trabajo sobre la interculturalidad ni sobre la ruralidad indígena, sino que las acciones son "igualitaristas", en el sentido del no reconocimiento programático de las diferencias culturales, y la ausencia de espacios de diálogo.

Cabe entonces adherir a la propuesta de Iriart y Spinelli en tanto que:

"El esfuerzo fundamental, a nuestro entender, debe estar puesto en salir de los falsos dilemas, señalar la existencia de un vacío, cuestionar las respuestas técnicas a los problemas sociales, políticos y científicos, reconocer la imposibilidad de generar respuestas desde un sector profesional y, a partir de ahí, crear con la población asistida y con los demás trabajadores de salud tipos de intervención alternativos" (6).

La similitud de algunos movimientos sociales juveniles mapuches con el actual fenómeno de los jóvenes en las "ciudades" de los suburbios franceses, quizás sirva como llamado de atención hacia la necesidad del reconocimiento del "otro" (7).

MARTHA ROSENBERG: La autora se sitúa autocríticamente desde el comienzo, es decir, que toma en cuenta cuál es su posición relativa ante las personas a las que va a atender: puede cambiar el nombre que da a la comunidad según los valores de uso corriente en cada época. Se identifica con el ejercicio del poder de nombrar. Sin embargo, el cambio de "reserva indígena" a "pueblos originarios" no ocurre espontáneamente, sino gracias a la acción política de dichos pueblos en los últimos años. Este cambio nos indica que hay en esa "reserva" un sujeto que no está inmóvil ni pasivo. En este caso, las mujeres, prolíficas o no, que quieren y deciden utilizar anticoncepción. Parece que avalada por su función pública, la autora se hiciera cargo de ejercer este poder, pero encuentra que no puede hacerlo si no es acompañada y mediatizada por los poderes establecidos y los equilibrios culturales en los que se sustenta la resistencia a estos cambios. Al proponer una acción contracultural como es la anticoncepción en las sociedades patriarcales, se ve confrontada a la necesidad de una toma de partido.

Nos advierte que se ampara y se inclina por la "normatización", es decir por la vigencia de una razón supuestamente universal que abarca todos los acontecimientos e impone un orden de simplificación (reducción de la complejidad y policausalidad de los eventos a una causa simple) y tranquilizan al colega al eliminar los puntos de conflicto con las propias creencias y razones (definición de una subjetividad por la pertenencia a un colectivo profesional médico). Acá el supuesto es que la anticoncepción puede ser encuadrada en la norma médica -simplificadacreando la ilusión de que el malestar en la sexualidad y la procreación humanos, y particularmente en "las" humanas, se soluciona con una intervención técnica.

"Una de las normativas vigentes en aquel momento, y aún hasta la fecha, es la entrega gratuita de anticonceptivos a todas las mujeres que pisen suelo neuquino y que los requieran (a esto lo llamamos ahora 'salud sexual y reproductiva', antes era 'planificación familiar')", dice.

También en este cambio de nombre hay un avance político: la biopolítica demográfica centrada en la familia y en la pertenencia territorial al suelo neuquino, se dice ahora "salud sexual y reproductiva", cuyo sujeto y agencia son ciudadanas/os habilitadas/os por derechos garantizados en la Constitución. "Yo pensaba, y sigo pensando, que cualquiera sea el título impreso, sigue siendo planificación normativa y sistemática por parte del poder". La autora no ha podido 
ejercer y pensar su práctica en la promoción de salud como desarrollo y ejercicio de potencialidades personales y derechos individuales, sino como mero cumplimiento de normas establecidas por el poder del que es agente, poder amasado con la explotación, la dominación de las mujeres y el racismo. En su inexperiencia, recurre a un traslado acrítico de las normas etnocéntricas dominantes (no sólo la Iglesia pretende que sus creencias sean la verdad revelada), que invisibilizan la diversidad de las culturas.

Cuando su propuesta logra captar para el programa a las mujeres, que se sienten interpretadas en su deseo, se produce la reacción de los varones dominantes damnificados por su atentado a la base de su potestad: el dominio de la fecundidad de las mujeres. La convocan a un diálogo de poder a poder. "Los hombres" con "la doctora". Las mujeres, ausentes, son mediadoras mudas entre ambos. Pero la ventaja de los hombres es que tienen claro qué quieren. No así la doctora, que no parece contar con la realidad del dominio patriarcal y el efecto de la anticoncepción autodeterminada de las mujeres sobre su economía de poder. No van a permitir que la fecundidad de sus mujeres esté expuesta a la intervención de un(a) tercer(a) en competencia (huinca que además representa a sus opresores) y no sólo a su autoridad normativa y su potencia generativa.

Resultado de pensar la salud como normativa abstracta a cumplir, y no escuchar las significaciones concretas que soportan las enfermedades y los eventos corporales en cada caso.

Las mujeres, en cambio, "escucharon en silencio, no se expresaron con palabras, pero no solicitaron más métodos anticonceptivos". Aquí aparece como mediadora entre los varones dominantes y las mujeres que, bajo el paraguas de la intervención médica, expresaron su deseo de separar la actividad sexual de la procreación. A pesar de la iniciativa de reunir a las mujeres para hablar de la cuestión, no pudo poner palabras donde no las había (mujeres que no pueden dirigirse al cacique) y permitir un diálogo entre las mujeres y los varones, que pudiera desplazar los usos tradicionales del cuerpo femenino como propiedad del colectivo de varones, tomados como representantes "naturales" de la cultura.
"El portero va por 14 hijos. El cacique sigue ostentando su cargo, gracias al voto de los hombres de su familia."

Todo sigue igual. Y se supone que la intervención fracasó. Lo que fracasa es tanto el etnocentrismo como el supuesto biomédico de que la anticoncepción es una práctica que actúa por sus efectos objetivos.

Para practicar una anticoncepción eficaz es necesario un posicionamiento subjetivo de las mujeres en la búsqueda de una sexualidad placentera y enriquecedora en sí misma, y no sólo en sus efectos reproductivos. La falta de este posicionamiento subjetivo está en la base de los innumerables "accidentes" (embarazos involuntarios o inoportunos) que en la literatura corriente de la salud reproductiva se atribuyen sólo a la falta de información e inadecuada utilización.

"Nosotros no avanzamos en el análisis, lo cual expresa nuestra coherente actitud frente al poder, en este caso al instituido en esa comunidad." Muy acertada la lectura de la dificultad de análisis de la propia práctica como una forma de cooptación por el poder instituido. En este caso, el poder patriarcal al desnudo.

ALICIA M. TORRES SECCHI: Desde la región de valles cordilleranos de Iruya -provincia de Saltadonde trabajo hace 27 años con comunidades collas, en servicios de salud con igual tiempo de experiencia de las estrategias de Atención Primaria de la Salud, se me ocurren las siguientes reflexiones:

Lo primero a decir es que puedo acompañar con cientos de ejemplos similares la brecha que existe entre el sistema público de salud, sus propuestas y prescripciones, y los caminos de bienestar y metas culturales de las poblaciones que asistimos. Esta distancia o conflicto, fundamentado en la lenta -por no decir nula- evolución de algunos indicadores sociosanitarios, aporta hacia algunos ejes de discusión:

a) Los objetivos del sistema de salud (no desde los discursos, sino desde las prácticas) siguen proponiéndose la protección de personas y no la protección de derechos. Desde un enfoque etnocéntrico, las políticas sociales asistencialistas, de las que la salud pública no 
está exenta, se ejecuta una biopolítica de las poblaciones más pobres a partir de supuestos no cuestionados científicamente.

b) Seguimos buscando un trabajo interdisciplinario (al menos, en buenas intenciones), contraponiendo el conocimiento científico con la "cultura y creencias de la gente". Nunca protegeremos derechos si no colocamos en una relación simétrica las diferentes formas de conocimiento y saberes, planteando como objetivo un trabajo intercultural claramente opuesto a las prácticas prescriptivas de consultorios, y de la educación sanitaria o promoción de la salud que realizamos.

c) La referencia del caso a que las mujeres aceptaron la prescripción que fue cuestionada por los hombres de la comunidad -de la que puedo dar también múltiples ejemplos similares- oculta dos procesos implícitos en las prácticas de los servicios de salud (consultorios o talleres educativos) que hay que cuestionar: 1) son espacios en los que quedan ocultas las personas no presentes, pero significativas para quien asiste. La poca técnica y práctica de escucha de los agentes de salud anula en tiempo y forma la posibilidad de expresión de las resistencias de quien recibe la indicación y 2) son relaciones institucionales asimétricas, donde las resistencias no se tramitarán de frente. Siglos de relaciones de tutela por parte de colonizadores, hacendados, docentes, médicos, curas, políticos, etc., configuraron como estrategia de sobrevivencia el no dar a conocer de frente y de primera intención sus opiniones y creencias. Práctica común de los adolescentes que los padres no reconocen, cuando van hacer algo que saben que los padres cuestionarán; lo hacen sin decir, ocultándolo como sobrevivencia básica al poder que no pueden cuestionar.

d) Las metas de la cultura de los pueblos aborígenes funcionan muchas veces como factores protectores en la adversidad en que viven, y el caso es ejemplo de ello: el tener muchos hijos, en culturas campesinas, es la única manera de poder enfrentar las múltiples tareas de producción y reproducción de la vida. Dar prescripciones parcializadas desde la cultura occidental, ignorando el contexto en que viven las poblaciones, se convierte en una verdadera iatrogenia. Es común que los profesionales suscribamos sin cuestionamientos las recetas de intervención de los organismos internacionales, que creen que la pobreza se resuelve disminuyendo el número de hijos de las familias pobres. La realidad demuestra el proceso inverso: mejora la calidad de vida de la gente, sus expectativas de estudios, mejores trabajos y automáticamente disminuye el número de hijos.

e) Preguntémonos ¿por qué la cultura de los servicios de salud es tan resistente a los saberes de la población, y a pesar de tantos años en que declamamos el respeto al derecho a decidir y a la cultura de la gente, seguimos recurriendo a la contradicción científica de desvalorizarlos primero para exigirles que cambien después?

MARIO TESTA: En una oportunidad asistí a una reunión donde había personas de África y América Latina, con organizadores de Estados Unidos de América y Europa. Se trataba de un "diálogo" entre países del tercer mundo, orientado por dichos organizadores, que pensaban iba a resultar muy provechoso para identificar problemas y oportunidades de los países subdesa... (¡perdón!, quise decir en fase de desarrollo).

Pero la cosa no anduvo bien: por alguna razón que no recuerdo, el supuesto diálogo se transformó en un reclamo de las mujeres europeas y norteamericanas presentes ante los machistas latinoamericanos y africanos por la situación de las mujeres en nuestros respectivos países (la cosa llegó hasta criticar a una mujer europea residente en México por usar aros en sus orejas con perforaciones).

Creo recordar (esto fue hace muchos años) que los hombreslatinoamericanos guardamos un silencio entre respetuoso y temeroso, como también las mujeres africanas, pero no así los hombres africanos, que defendieron las prerrogativas masculinas en tono airado, y poco faltó para transformarse en agresión abierta.

¿Parecido a Mallín? Así me parece. No es un tema menor. Los derechos masculinos en algunos países de África Ilegan a la amputación del clítoris, la sutura de los labios mayores hasta lo que se considere edad de merecer (diría mi abuelita) u otras delicadezas por el estilo, llegando a la lapidación para las adúlteras. 
Mirado del otro lado, antes de actuar habría que saber la razón por la que se tiene tantos hijos, que puede ir desde el mandato religioso, la tradición cultural, el prestigio sexual hasta la motivación económica. Sabemos que la mortalidad infantil rural es mayor que la urbana, pero a la familia rural ise les mueren más porque tienen más hijos, o tienen más hijos porque se les mueren más?

Y claro, las respuestas de nosotros, bienpensantes y políticamente correctos, es hacer lo que corresponde al buen pensamiento y la corrección política, que se expresa de múltiples maneras según las circunstancias. $O$, para decirlo con palabras del Dr. Rubén Ferro: cuando el médico se asusta, diagnostica y medica; cuando el psicoanalista se asusta, interpreta; cuando el planificador se asusta, normatiza (agregaría yo).

Conclusión (por ahora): la planificación normativa dies hard (f).

\section{SEGUNDA RONDA DE OPINIONES}

MARTHA ROSENBERG: Me llamó la atención en algunas de las respuestas de mis colegas, que la cultura de la que se trata parece ser tomada como una malla inextensible, fijada en y por el dominio masculino patriarcal, que contiene a las mujeres, excluyéndolas como menores e incapaces de modificar los significados culturales impuestos a su sexualidad y su capacidad reproductiva. Por mi parte, creo que una cosa es respetar la diversidad y otra es congelarla, privándola de la dinámica histórica que en toda sociedad desplaza valores y sentidos aparentemente inamovibles. Las tecnologías del cuerpo (anticoncepción incluida) quedan esterilizadas en su potencialidad de subjetivar los grados posibles de autonomía que estas prácticas habilitan, aunque se inicien sin clara conciencia de sus consecuencias sobre los vínculos establecidos como "saludables".

La sexualidad, reducida a su condición reproductiva, es la figura en la que retorna lo reprimido en la campaña civilizatoria preventiva: contener la reproducción de los pueblos originarios es mejor que matarlos, o "reservarlos", enquistados en una burbuja intemporal de exclusión de los bienes culturales y materiales de los que gozan los sectores sociales dominantes.

"Todo sigue igual", dice A. Feltri. Continuidad incólume por no haber sostenido la discontinuidad que introdujo su intervención en la tradición cultural mapuche. Hay tendencia a hacer una defensa acrítica y totalizante de esta y otras "culturas originarias", como si bastara con este calificativo para otorgarles superioridad sobre las que, teniendo otros orígenes, han sometido durante siglos a las poblaciones originarias.

El punto en el que es posible instalar una política de salud reproductiva sustentable no suele ser el que ofrece "el supuesto biomédico de que la anticoncepción es una práctica que actúa por sus efectos objetivos" (g). Es decisiva la capacidad de un grupo para construir activamente rituales que signifiquen el cuerpo femenino como sede de poder y no de sometimiento, ya sea a la voluntad masculina o a la legalidad biológica. Para eso y por eso hablamos de "empoderar" a las mujeres con conocimientos, instrumentos técnicos, jurídicos y políticos para construir su subjetividad en una igualdad -contracara de la jerarquización de géneros- garantizada por los derechos humanos. No se trata de igualdad entre los sexos: sería un contrasentido en los términos, ya que sexo es diferencia. Se trata, sí, de la igualdad de derechos, que no ocurre espontáneamente sino a través de las acciones políticas que la instauren en la forma concreta de la equidad de género. Tal vez habría que preguntarse si se puede hablar de eficacia de un dispositivo de salud y, en especial, de salud reproductiva, que no construya activamente a sus beneficiarias y beneficiarios como sujetos de derechos. La diversidad étnico-cultural debe ser considerada en el marco de la universalidad de los derechos adquiridos por el hecho de integrar o pertenecer a determinada comunidad.

Como señala Torres en su comentario (h), existe "una brecha entre el sistema público de salud, sus propuestas y prescripciones y los caminos de bienestar y metas culturales de las poblaciones que asistimos". Pero esta brecha siempre existe cuando las políticas inciden en las pautas tradicionales básicas. Incluso cuando la cultura desde la que se planifica es similar a la de I@s destinatari@s de las políticas. Lo que no es aceptable -ni posible- es imponer autoritariamente 
nuestros fines ilustrados, así como tampoco lo es conceder a las tradiciones cuando sostienen relaciones y prácticas evidentemente patógenas -no sólo en términos biomédicos- como por ejemplo la violencia contra las mujeres, el abuso sexual, la maternidad precoz y/o involuntaria, la multiparidad que no respeta los intervalos intergenésicos adecuados, como señala Maglio en su comentario. Concuerdo en que lo simbólico debe ineludiblemente ser considerado en cuanto factor etiológico.

A las preguntas propuestas por Ynoub sobre la situación: ¿Qué es? ¿Qué debe ser? ¿Qué es deseable cambiar de ella y qué no?, habría que agregar: ¿Para quién es deseable cambiar qué? ¿Para quién no? Cada uno de los sujetos que menciona (la comunidad, el Estado, el mercado) está lejos de ser homogéneo, dice. Especialmente en el caso de la comunidad y respecto de la salud reproductiva, considerar un punto de vista único sería pasar por alto las diferencias que la circulación de poder genera al atravesar las relaciones sociales y sexuales. Diferencias sexuales, de género, de edad, cruzadas por las económicas y sociales (cacique, portero de la escuela, mujeres solteras, multíparas, niñas, varones) determinan intereses diversos. Los cambios deseados y buscados por algun@s sujet@s, son resistidos por otr@s. Especialmente aquellos que comprometen el dominio de la reproducción de la sociedad, instituido por el colectivo intergeneracional e interclasista de los varones como lugar del origen y sostén de "la cultura", y contrapuesto a la naturalización del papel de las mujeres en su calidad de hembras-madres.

En este caso, la médica, provista del programa de procreación responsable, es víctima de su propia ingenuidad respecto de las determinaciones que normatizan las conductas sexuales. La sexualidad está sujeta a las relaciones de poder, y las prácticas que permiten a las mujeres desarrollar agencia sobre su sexualidad y su capacidad de procrear, como la anticoncepción autónoma, conmueven el poder patriarcal. No sólo en sus depositarios explícitos, sino también en el mundo intrapsíquico de las que identifican ser mujer con el sometimiento al destino maternal y la pasividad ante los deseos sexuales masculinos, apuntalando esa lógica de dominación.

La aceptación por parte de las mujeres de la propuesta anticonceptiva puede ser leída tanto como aceptación acrítica de la autoridad médica, como una oportunidad para reformular deseos propios de una heterosexualidad no reproductiva. En ese sentido, no sólo hay, como señala Luis Justo en su aporte, un conflicto intercultural no planteado, sino además un conflicto intracultural no planteado. Parecería que la cuestión de la dominación de las mujeres y la posición subjetiva que este dominio les depara en su comunidad no es relevante para el destino de una intervención de prevención primaria sobre su salud, como la descripta por Feltri.

La violencia epistémica (i) también puede consistir en "saber" que lo valioso es conservar los rasgos originarios de una cultura y ser sord@s a los síntomas que nos interpelan desde las milenarias relaciones de género, cuando emerge un sujeto político que ejerce y demanda titularidad de derechos sobre su cuerpo. La legislación sobre salud reproductiva le debe mucho a las luchas emancipatorias de las mujeres. Responder al bio-poder con bio-políticas protagonizadas por aquell@s a quienes toma por objeto es dislocar el dispositivo reproductor.

El disciplinamiento de la sexualidad y de las relaciones de género no es patrimonio exclusivo de las políticas estatales. Los dispositivos de la sexualidad en una cultura patriarcal originaria son tanto (o más) disciplinadores de las mujeres y varones que los del estado moderno. Por eso, no hay salud reproductiva ni sexualidad responsable sin construcción de relaciones de género que respeten la autonomía de las mujeres en sus definiciones y decisiones sexuales y reproductivas. Habrá que poner en juego a todos los actores, incluidos los médicos, en un marco de respeto y promoción de los derechos, transmisión de conocimientos, debate de los problemas y construcción de fines sociales compartidos.

FLORENTINO J. PICHÚN: Es difícil analizar una situación planteada desde afuera y concebida desde una cultura burguesa, etnocéntrica, donde se mide la necesidad del otro desde un "yo" que está convencido de ser poseedor de una cultura superior y cuyo sistema de valores le permite determinar las carencias ajenas. Más aún cuando se trata de individuos o grupos que están lejos de la civilización, rozando la barbarie, que viven en 
condiciones que para ellos es complejo siquiera imaginar, que migran en verano hacia la cordillera y no les importa dejar todo lo que han construido en lo que llaman la invernada y luego hacer lo mismo para volver al lugar de invernada para que los chicos puedan o no ir a la escuela, puedan o no estar vacunados o incorporados a un sistema de salud pública, que por otro lado las abuelas o los propios padres saben que en los años cincuenta $y$ sesenta, o antes, nada se sabía de todo esto, y sin embargo se vivía igual, sanos y con esperanza de trascender, y aquí hay algo importante: esa trascendencia se logra a través de la procreación. El hijo varón también tiene una importancia distintiva, ya sea por esa trascendencia o para el trabajo, al que se incorpora a una edad temprana.

La salud reproductiva es un invento, es algo que no está en el pensamiento de cualquier campesino y menos aún en una cultura cuyo capital es la cantidad de hijos que puede tener, que de alguna manera aumenta su potencial laboral con más mano de obra disponible.

Por otro lado, los programas sociales que se ponen en práctica nunca tienen la mirada de las poblaciones originarias, en este caso, pero de ninguna población destinataria. Siempre se ha hecho una planificación muy dirigida, orientada y centralizada, y al momento de ponerla en práctica, la población se siente absolutamente ajena a sus valores, es algo externo a la comunidad y su efectividad se reduce, más aún cuando la salud reproductiva no es una necesidad que la comunidad visualice como problema. Todo lo contrario: se ve como una invasión, una intromisión en su destino como familia.

Además de todas estas dificultades, atribuibles a factores técnicos de concebir programas sociales destinados a distintas poblaciones, es importante considerar la ideología que subyacen en éstos y en todos los modelos hegemónicos que siempre subalternizan a cualquier cultura, a veces en forma consciente, otras veces en forma inconsciente.

Ese prejuicio con que se establecen estas relaciones de uno y otro lado hace difícil la comunicación y, en consecuencia, el aprendizaje de ambos lados, sumado a otras experiencias nada felices que los pueblos originarios han vivido con distintos actores del Estado o individuos particulares (Dirección de tierras fiscales, guardabosques, sanidad animal, mercachifles, etc.) y que no ayuda a generar confianza entre las partes.

En el caso de Adriana, posiblemente tampoco estuvo pensando el modo de intervención en la familia, con participación de algún miembro de la comunidad que hiciera de nexo entre el sistema de salud y la comunidad originaria, lo que no sería novedoso porque es el modelo hegemónico que aún hoy perdura y responde al paradigma dominante y eurocéntrico que se aplica en todos los programas, eso por un lado. Por el otro lado está el trabajo que el modelo cristiano en sus diferentes versiones también influye y confunde, poniendo en crisis cualquier proyecto común en comunidades de pueblos originarios, población rural o cualquier población urbana marginal en situación de pobreza o exclusión social.

Yo personalmente abogo por lo que se denomina "unidad en diversidad", donde todos participan de un modelo común respetando la diversidad étnica, cultural, social, económica e ideológica. Lo que sin lugar a dudas requiere de un cambio en los modelos ideológicos de los aparatos del Estado, fundamentalmente en el sistema formador de la universidad, además de aquellos que intervienen en la administración de justicia. En definitiva: un modelo social distinto, inclusivo, integrador e integrado.

ROXANA YNOUB: Encuentro grandes coincidencias entre los comentarios que promovió la rica reflexión de la Dra. Feltri.

No es sencillo hacer una síntesis de ellos que se mantenga fiel, en tan breve espacio, a los aportes de cada uno. Optaré entonces por retomarlos en el marco de las impresiones generales que me suscitaron.

Una evocación que se (me) impuso -al volver a leer todo el material- fue la desafiante afirmación de Sigmund Freud según la cual existen tres tareas imposibles: gobernar, curar y enseñar.

¿De qué manera entiendo que se aplican en este caso?

En principio, todos (me refiero a los autores de los comentarios) aceptamos que el Servicio de Salud y las políticas de Salud -en este caso en particular, de Salud Sexual y reproductiva- deben 
existir. Dicho de otra manera, ninguno de nosotros sostuvo que sería deseable eliminar la oferta asistencial, es decir, "dejar librada la comunidad a su suerte, y a su propia dialéctica de desarrollo". Por el contrario, los comentarios se situaron en un continuo entre posiciones de máxima y de mínima con relación a qué es lo que se debería hacer o qué es lo que debiera ser una política de salud. De modo que todos partimos del supuesto de que es deseable alguna intervención.

Admitimos además una supuesta situación problema (o una problemática): alta fecundidad y alta mortalidad. Con mayor o menor nitidez y convencimiento, reconocimos también el "sometimiento" de la mujer a un régimen patriarcal (el de la cultura de esa comunidad, Mallín) como un problema asociado a esta problemática.

De modo que la cuestión asistencial strictu sensu no estuvo cuestionada; lo que se cuestionó, en todo caso, es qué y cómo debería asistirse.

Esa "vocación asistencial" nos ubica de Ileno en el contexto de las "tareas imposibles" descriptas por Freud.

Pero ¿por qué tareas imposibles?

Pensemos por ejemplo en la tarea de enseñar. Una perspectiva simplificadora se representa esta tarea como un "transvasamiento": lo que uno tiene (por ejemplo, un cierto saber) lo transfiere o lo vuelca en el otro, que lo recibe como el vaso recibe el agua que se vierte desde una botella. Resulta claro, sin embargo, que esta imagen no se condice con la experiencia de "encuentro" entre el mundo de sentidos y significaciones de cada parte, que requiere el "enseñar-aprender".

Pero además, para aprender debe existir el deseo de aprender; y éste sólo es posible si alguna circunstancia pone en cuestión (los piagetianos dirían "desequilibra") los saberes (o los sentidos) ya disponibles. De allí que gran parte del arte docente estribe en el ejercicio de la revisión crítica de lo que se acepta como ya sabido o conocido -al estilo de la mayeútica socrática (en esa dirección habría que reconocer también que debe existir concomitantemente un deseo de enseñar y que la experiencia de enseñanza también es una experiencia transformadora para quien la protagoniza).

Ahora bien, esa experiencia de encuentro que concebimos como necesaria parece ser, en cierto punto, siempre fallida: el otro no está donde se cree o se lo concibe; los conocimientos se tejen según contextos significantes e intertextualidades que cada uno construye y reconstruye conforme a historias y recorridos singulares. El aprendizaje implicará siempre una experiencia protagónica (resaltaría lo de agónico) no transferible, por la que el propio sujeto debe andar el camino de la puesta en crisis de sus propias posiciones (tomar contacto con su ignorancia, pedía Sócrates) para la conquista de nuevas perspectivas y sentidos.

De todo ello se concluye que la única posibilidad de viabilizar los encuentros comunicativos que requiere el proceso de "enseñanzaaprendizaje" es siendo parte de una historia común, en la que se ha construido algún campo de sentido compartido.

Dado que no es posible extenderme en estas consideraciones, me limitaré a rescatar los conceptos que a mi juicio resultan útiles para el asunto que nos ocupan.

Uno de ellos se sintetiza en el concepto -también psicoanalítico- de demanda.

No interesa profundizar aquí en el alcance que este término tiene en el ámbito psicoanalítico; alcanza con señalar que para que el proceso de la cura tenga alguna viabilidad, los psicoanalistas piensan que éste debe iniciarse apoyado en la demanda del sujeto. Si esta demanda no está instalada, el sujeto no está en condiciones de buscar (o de "encontrarse" con) un camino de transformación. A su turno, esta demanda surgiría o se desencadenaría como resultado de una situación vital conflictiva o traumática que provoca malestar, sufrimientos, síntomas.

La pregunta sería entonces: ¿quién demanda?; y si demanda, ¿qué y a quién demanda? en la comunidad Mallín.

Aparentemente nos encontramos con situaciones de sufrimiento objetivas: alta mortalidad, sometimiento patriarcal de la mujer, avasaIlamiento colonial, pobreza, etc., etc., etc. Pero, -y a mi juicio es allí donde se instalan todos los problemas- ¿este sufrimiento se transforma en demanda de atención? Y si se contesta positivamente, ¿es al sistema de salud del Estado a quien demanda la comunidad?

El sistema de salud, a su turno, toma (ateniéndonos al relato de la Dra. Feltri) sólo 
algunos aspectos de las condiciones vitales de la comunidad y los interpreta como síntomas que deben ser asistidos y deseablemente revertidos. Por ejemplo, la "alta natalidad". Identifica el síntoma y lo atiende.

Surgen entonces los problemas: desencuentros, incomunicación, impenetrabilidad intercultural, y todas las definiciones que resta imaginar.

¿Qué hacer frente a ello? ¿Esperar que la comunidad (o las mujeres) demande(n)? ¿Saber escuchar la demanda? ¿Ponerse en condiciones de ser demandado? ¿Crear la demanda (como se dice en marketing)? Son opciones posibles.

Hay que advertir, sin embargo, que cualquier acción asistencial (aunque sea "tan loable" como contribuir a mitigar el poder patriarcal de esa comunidad y horizontalizar las relaciones de género) conlleva una acción de transculturización. Por lo que la intervención implicará siempre una toma de partido ética (es decir, del ethos implícito), moral y política. ¿Es posible una intervención como esa sin involucrarse en una historia común -que trasciende con mucho la cuestión de la anticoncepción- con la comunidad asistida? Y si la construcción de esa historia común fuera posible, ¿está preparado el profesional de la salud para dejarse transformar también por ella?

Se me ocurre que las respuestas a estos dilemas sólo pueden surgir de los actores implicados en esas experiencias. Entre los actores incluyo, por supuesto, a los propios profesionales de la salud que batallan en medio de tan difíciles derroteros.

Deseo hacer una última consideración: las tensiones implicadas en estas relaciones asistenciales no son privativas de la comunidad analizada, ni de las comunidades de pueblos originarios, ni de las mujeres de estas comunidades. En sus aspectos estructurales son comunes a todo esquema asistencial, cualquiera sea la naturaleza de los sujetos protagonistas de ellas. Atañen a esa dimensión por momentos irresoluble que advirtió Freud.

LUIS JUSTO: La lectura de los comentarios permite observar la presencia de algunos tópicos comunes, tales como la percepción de formas tácitas de resistencia anticolonial a través del rechazo de prácticas impuestas por los agentes de salud, la diversa significación de la multiparidad para las/los actoras/es, el conflicto entre individuo y comunidad, el cambio en la cosmovisión local a consecuencia de la colonización, la mirada universalista desde los derechos humanos, etc. Sin embargo, interesa notar que de las diversas perspectivas surge también una cierta idea de heterogeneidad, de ausencia de críticas lineales y recetas evidentes. La intersección de problemas complejos tales como la triple condición vulnerable de la mujer en el ámbito cordillerano (mapuche, mujer y pobre) hace necesario este tipo de ejercicio de múltiples miradas, que quizás prefigura la dificultad de llegar a soluciones deliberativas y consensuadas, en las que todos los afectados puedan participar como "hablantes simétricos". En este sentido, la propuesta de Boaventura de Sousa Santos (8), de trabajar desde la percepción de la incompletitud de la propia cultura a través de lo que Ilama la construcción de una "hermenéutica diatópica", en tanto que permite el diálogo desde sitios/lugares diversos, sea una vía para intentar la resolución de situaciones de conflicto cultural. En la medida en que cada cultura se perciba como pudiendo brindar respuestas completas a los interrogantes que surgen del contacto intercultural, la posibilidad de este diálogo se clausura, perdiéndose así su potencialidad emancipatoria. Así como la mirada colonial es de clausura, la percepción de nuestro mestizaje abre la posibilidad de trabajar en los intersticios de las "culturas híbridas" en las que la creación y el diálogo sean posibles a través del "pensamiento fronterizo" (border thinking según Mignolo) (9).

Cabe agregar, a modo de comentario lateral, el riesgo de las posiciones que expresan visiones neo?coloniales de problemas que, en Latinoamérica, tienen rasgos propios. Citando a Patricia Richards (10):

“Existe además una discriminación en contra de las mujeres indígenas, sus creencias y sus formas de vivir, perpetuada por los movimientos de mujeres de la sociedad dominante y las políticas estatales de género. Al intentar organizarse en torno a sus prioridades, las mujeres indígenas han encontrado difícil evitar que sus prioridades y discursos sean apropiados o distorsionados por los movimientos de mujeres no indígenas, que tienden a encajar a las mujeres indígenas dentro de una causa monolítica de la mujer. O sea, intentan 'asimilarlas' a una identidad única de la 
mujer. Tal como me explicó una mujer mapuche: 'Ha sido bastante duro... con mujeres que no son indígenas que generalmente quieren que uno como indígena se someta a los cánones que ellas tienen, a la forma de organización de ellas, a la estructura de ellas, a la visión de ellas y no se dan cuenta de que nosotros somos pueblo distinto... Te miran de repente como estas pobrecitas indígenas que hay que ayudar, que hay que hacer esto, que hay que hacer lo otro. ... No te ven como distinto y como que uno puede aportar. Yo te digo, eso es muy duro (entrevista)'." "...los movimientos de mujeres de la sociedad dominante y los organismos estatales de la mujer, como el Servicio Nacional de la Mujer (SERNAM [México]), no admiten la posibilidad de que las relaciones de género funcionen de manera distinta dentro de los pueblos indígenas. O sea, no dejan espacio para las diferencias entre las mujeres.

Tanto las mujeres mapuches como las mujeres indígenas de muchos pueblos de los EE.UU. hablan de relaciones complementarias entre hombres y mujeres. Muchas feministas resisten creer que tales relaciones sean posibles y aseguran que los hombres indígenas son machistas como cualquier otro. A esto, muchas mujeres indígenas contestan que si existe machismo dentro de sus pueblos hoy, es como resultado de la infiltración de la cultura y la religión occidental en sus pueblos."

Esta situación recursiva muestra cómo una lucha por la emancipación como la de la mujer puede sin embargo funcionar como contraemancipatoria respecto a la de otros colectivos (en este caso, las mujeres indígenas) al sostener dentro suyo visiones coloniales cuya estructura deriva de un tardío aunque persistente eurocentrismo.

MARIO TESTA: Muy bien, ahora está todo claro, lo más seguro es que quién sabe.

Hay coincidencias frecuentes en las respuestas iniciales, como las persistentes críticas a la planificación normativa. Propuesta: enviar esa conclusión a los organismos oficiales de planificación, en todos los niveles de la administración, porque no se trata sólo del caso Mallín, sino que abarca, como diría monseñor (no mi señor) Baseotto, urbi et orbi (j).

Y sigo de acuerdo con quienes piensan en la necesidad de saber más acerca del problema concreto, del que está sometido a las múltiples determinaciones del aquí y ahora, el de la comunidad de Mallín en el siglo XXI.

Pero no con el significado del diagnóstico de salud, como lo hacíamos (¡ay!) en el método CENDES/OPS, sino para identificar la situación (Carlos Matus dixit) con todos sus más y sus menos.

Y pienso que encontraríamos, no en la superficie, sino ocultas tras un manto de piadoso silencio, las contradicciones -por otra parte ya reveladas- que atraviesan el relato y sus interpretaciones en la primera vuelta de estos comentarios.

Y si de contradicciones se trata, pienso (ya lo dije alguna vez) que éstas no se resuelven sino que se utilizan -las utilizamos- mal o bien, para crecer o para destruirnos (cada uno de nosotros individualmente, o como grupo).

Contradicción flagrante: las mujeres mapuches querrían tener menos hijos, los hombres no. Resolución (para contradecirme, una vez más, con el párrafo anterior): el poder masculino triunfa sobre la (falta de) estrategia de las mujeres y de la médica interviniente. Fin del problema (¿o no?).

Conclusión (ahora final): más diálogo; entre nosotros, como éste que estamos Ilevando a cabo gracias a Salud Colectiva, entre nosotros (quienes corresponda) y ellos (si fuera posible, o mejor dicho, buscando la manera de hacerlo posible), y entre ellos (eleven sus rezos los partidarios de este instrumento). 


\section{NOTAS FINALES}

a. La coordinación del trabajo y la organización del artículo fueron realizadas por Jorge Arakaki, editor asociado y Hugo Spinelli, editor responsable de Salud Colectiva.

b. El término Mallín significa suelo húmedo propicio para la pastura; no se hace referencia al nombre de la comunidad con el fin de preservar la identidad de las personas involucradas en el relato.

c. La autora es integrante de la VIII cohorte de la Maestría de Epidemiología, Gestión y Políticas de Salud, de la Universidad Nacional de Lanús, con sede en la ciudad de Neuquén.

d. Estos comentarios se inspiran en un conjunto de conceptos tomados del texto de Juan Samaja: Epistemología de la Salud. Reproducción social, subjetividad y transdisciplina. (2). Dado que se trata de una reflexión aplicada al análisis de una situación particular, se omiten las referencias o citas textuales.

e. Las cuestiones sobre fecundidad y derechos humanos se fueron incorporando muy progresivamente: el concepto de "decisión libre y responsable acerca del número y espaciamiento de los hijos a tener" fue declarado derecho humano por primera vez recién en 1968 (art. 16 de la Proclamación de Teherán, ratificado en 1969 por la Declaración de Progreso Social y Desarrollo y luego por diversos documentos de las Naciones Unidas). (cfr. Cervantes Carson A. De mujeres, médicos y burócratas: políticas de población y derechos humanos en México) (3).

f. Duro de matar.

g. Citado de mi primer comentario, (p.307).

h. Ver el comentario de Alicia M. Torres Secchi, en la primera ronda de opiniones (p.307).

i. Ver el comentario de Luis F. Justo, en la primera ronda de opiniones (p.306).

j. Aclaración de los editores: Antonio Baseotto es el actual obispo castrense. Opina, según se ha difundido en medios periodísticos, sin que haya sido desmentido, que distribuir preservativos "es propiciar el libertinaje sexual y difundir impunemente el SIDA".

\section{REFERENCIAS BIBLIOGRÁFICAS}

1. Menéndez E. Medicina y cultura. Barcelona: Bellaterra; 2000. p. 163-188

2. Samaja, J. Epistemología de la Salud. Reproducción social, subjetividad y transdisciplina. Buenos Aires: Lugar Editorial; 2004.

3. Cervantes Carson A. De mujeres, médicos y burócratas: políticas de población y derechos humanos en México. En: Pérez G, et al. Etica y Salud Reproductiva. México: UNAM; 1996.
4. Samaja J. Temas y ejes conceptuales de la convocatoria al Seminario Internacional sobre Perspectivas en la Salud Familiar y Comunitaria en las Sociedades del Conocimiento. Concepción del Uruguay, 2005. (Mimeo).

5. Castro Gómez S. Ciencias sociales, violencia epistémica y el problema de la "invención del otro". En: Lander E, compilador. La colonialidad del saber: eurocentrismo y ciencias sociales. Perspectivas Latinoamericanas. Buenos Aires: CLACSO; 1993. 
6. Iriart $\mathrm{C}$, Spinelli $\mathrm{H}$. The sanitary question in the modernity-postmodernity debate. Cadernos de Saúde Pública. 1994;10(4):491-496.

7. Kropff L. Activismo mapuche en Argentina: trayectoria histórica y nuevas propuestas. En: Davalos $\mathrm{P}$, compilador. Pueblos indígenas, estado y democracia. Buenos Aires: CLACSO; 2005.

8. Sousa Santos B. Toward a Multicultural Conception of Human Rights. En: Berta Esperanza Hernández-Truyol, editora. Moral Imperialism. A Critical Anthology. New York: University Press; 2002 [en línea] 2005 [fecha de acceso 31 de julio de 2005]. URL disponible en: http: //lic.law.ufl.edu/ hernandez/Women/ch02.pdf

9. Mignolo WD. Local histories/Global Designs. Coloniality, Subaltern Knowledges and Border Thinking. Princeton: Princeton University Press; 2000.

10. Richards P. Las demandas de las mujeres indígenas: impresiones comparativas en EEUU y Chile. En: Aylwin JO, editor. Derechos humanos y pueblos indígenas: tendencias internacionales y contexto chileno. Temuco: Instituto de Estudios Indígenas/Universidad de La Frontera; 2004. p 211.

\section{FORMA DE CITAR}

Feltri AA, Arakaki J, Justo LF, Maglio F, Pichún FJ, Rosenberg MI, Spinelli H, Testa M, Torres Secchi AM, Ynoub RC. Salud Reproductiva e Interculturalidad. Salud Colectiva. 2006;2(3):299-316.

Recibido el 21 de junio de 2006

Versión final presentada el 8 de septiembre de 2006

Aprobado el 6 de octubre de 2006 